\title{
El perfil intelectual de Octavio Paz
}

El reciente deceso del escritor mexicano Octavio $\mathrm{Paz}$ ha provocado una reacción unánime de pesar y exaltación de su trascendencia como literato y hombre de ideas. Dejando de lado cuestiones que pertenecen al fuero personal, considero oportuno destacar dos aspectos notables de la figura de Octavio Paz: en primer lugar, su obra, rica, compleja, diversa; en segundo lugar, su conducta intelectual.

De la poesía lírica de Paz se ha dicho bastante. Es uno de los principales poetas latinoamericanos y esta faceta de su obra dará sin duda mucho que hablar y discutir a generaciones venideras de estudiosos. El autor se definía personalmente como poeta y ésta era la vertiente de su obra que tenía en mayor estima y consideración. Sin restarle su debido valor, sospecho que su contribución más duradera debemos buscarla en su extensa obra ensayística. Su aporte no radica únicamente en la peculiar textura de su prosa, acertadamente descrita por Miguel García-Posada como "resultado de una magistral simplificación de la sintaxis, que se traduce en fulgurantes yuxtaposiciones y en la acelerada velocidad de los enlaces... El discurso avanza como una proa sobre un mar domesticado". Pero el valor de los ensayos de Paz está en la originalidad de sus ideas, que para elaborarlas es capaz de hacer concurrir una amplia variedad de ámbitos de conocimiento en los que se desenvuelve con envidiable autoridad y soltura. La calidad literaria del ensayo de Paz consiste, pues, en aunar los hallazgos formales y de fondo, cualidad poco común hoy en dia donde tiende a instituirse una escisión entre la escritura "prosaica" de los especialistas y la prosa "ensayística" de ciertos literatos, cuyo don principal consiste en la hermosa ornamentación de lugares comunes.

No alcanzaría el espacio en este comentario para hacer un inventario completo de la impresionante obra ensayística de Paz. Tal vez baste enumerar algunos ejemplos donde queda patente su contribución al pensamiento latinoamericano. El Laberinto de la soledad es unánimemente celebrado como el documento por excelencia de la "mexicanidad". Menos unánime ha sido caer en la cuenta de que Paz explora la "mexicanidad" de manera bastante audaz y sin parelelos en las ciencias de la cultura. En dicho ensayo se combina un estudio heterodoxo de la decantación del proceso histórico en el registro popular del lenguaje para proponer un modelo de la psicología colectiva del sujeto nacional mexicano. Paz evita salidas fáciles como el determinismo racial biologista al estilo de Carl Jung y se acerca sorprendentemente a una propuesta que, varias décadas después, elabora el brillante sociólogo alemán Norbert Elias. Este pensador propone el estudio de un "habitus nacional" en las prácticas simbólicas en una serie de ensayos sobre la génesis del nazismo.

Es importante aclarar, sin embargo, que Paz nunca pretendió sociología ni hablar como hombre 
de ciencia o conocimiento. Hábilmente escamoteó los límites del rigor científico asumiendo la posición de hombre de letras, que podía hacer uso libre e imaginativo de ideas prestadas de la filosofía, la historia y la ciencia social, ámbitos del conocimiento que - a diferencia de ciertos literatos puros de hoy- nunca despreció sino que leyó con la curiosidad y clarividencia propios de una inteligencia renuente a dejarse encerrar entre linderos disciplinarios.

En El laberinto de la soledad, encontramos algunos ensayos que han merecido menor atención por parte de la crítica pero que también aportan ideas sugerentes y novedosas. Al hacer su propio balance de la Revolución Mexicana, Paz la compara con la Revolución Bolchevique y la Revolución China, y nota afinidades entre todos esos procesos en cuanto constituyen manifestaciones inequívocas de la irrupción de países periféricos al protagonismo de la historia moderna de Occidente. Esta intuición ha sido trabajada después por historiadores profesionales que casi seguramente desconocían la obra de Paz.

El extenso volumen Sor Juana Inés de la Cruz o las trampas de la $f e$, además de ser un estudio imprescindible para la vida y la obra de esa gran escritora, tiene una sección introductoria que es uno de los estudios más esclarecedores sobre la vida en el Virreinato de la Nueva España y la América colonial. Allí se pone de manifiesto el esfuerzo de Paz por tratar de comprender el enredado proceso histórico de su país desde su propia especificidad, y no desde cómodas etiquetas prestadas de éste o aquel manual de historia.

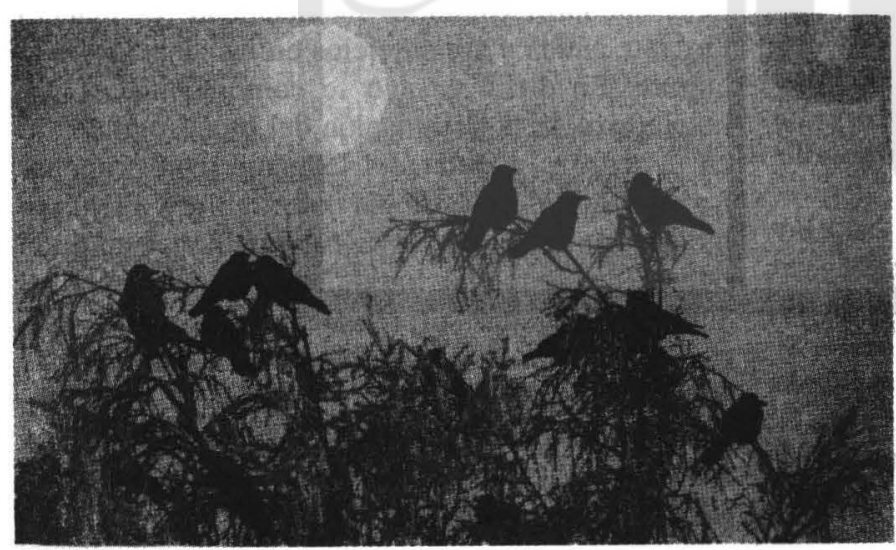

Lugar central dentro de la producción ensayística de Paz ocupa la obra dedicada a pensar su gran pasión vital: la poesía. Destacaré dos vertientes. La primera de ellas está dedicada a explicar el ser de la poesía y su ubicación compleja y contradictoria dentro de la cultura de la modernidad. Aquí encontramos la espléndida trilogía compuesta por El Arco y la lira, Los hijos del limo -obra derivada de la serie de conferencias dictadas en la cátedra de poesía Charles Eliot Norton de la Universidad de Harvard- y La otra voz. A Paz debemos la brillante fórmula para definir la lógica de la evolución del lenguaje poético luego de la revolución romántica, "la tradición de la ruptura", una paradoja que sintetiza el complejo dinamismo de tradición e innovación que subyace al cambio literario. La otra vertiente de ensayo poético es la explicación de la obra de otros poetas y artistas, donde Paz hace gala de la riqueza de su cultura literaria y de la facilidad para comunicar al lector promedio los intrincados mecanismos de esta producción artística. Esta obra ocupa varios abultados volúmenes de su Obra Completa, pero destaca entre ellas como ejemplo de amenidad, claridad y lucidez Cuadrivio, dedicado a explicar la poesía de Rubén Darío, Fernando Pessoa, Luis Cernuda y Ramón López Velarde.

También dedicó Paz una parte considerable de su obra ensayística al esclarecimiento de cuestiones políticas de trascendencia para su país y la humanidad contemporánea. Allí encontramos la parte más polémica de su pensamiento. Ferviente admirador de los movimientos revolucionarios de izquierda en su juventud - no debemos olvidar su decidida participación en pro de la causa de la República Española y su fallido intento de incorporarse a las filas de sus combatientes-, se constituyó en uno de los críticos más acerbos e inclaudicables del socialismo real. Décadas antes de que el antimarxismo se pusiera de moda en los círculos intelectuales - moda a la que Paz y su trabajo de promotor cultural indudablemente contribuyeron-, denunció los peligros de una visión de la sociedad que fácilmente inmolaba la libertad en aras de una igualdad en gran medida producto de una ilusión ideológica.

Hay que decir, en descargo de las acusaciones de "reaccionario" y "neoli- 
heral" que Oclavio Paz recibió perennemente de sus detractores, que su posición -al menos vista a la luz de sus argumentos- distó de ser dogmática y carente de matices. En Itinerario - lo más próximo dentro de su obra a una autobiografía intelectual- insiste en que el capitalismo, lejos de ser una panacea para la salvación de la humanidad, padece de males inherentes ante los que la democracia liberal no es contrapeso suficiente. Admite que si bien el mercado es un mecanismo más eficiente para organizar la producción que la planificación estatal centralizada, no por ello debe ignorarse su potencial destructivo. Por esta razón, Paz prefiere definirse como un crílico de la modernidad que como un defensor a ultranza de Occidente o un adversario del socialismo real. $Y$, en este sentido, reivindica la tradición crítica que la modernidad inaugura. Así, ubica esta tradición tanto en lo que denomina 'tradición de la ruptura', es decir, la cultura literaria moderna, como en la vocación hacia la disidencia inserta en las instituciones y cultura de la democracia liberal. Este es el legado más valioso del que dispone la humanidad contemporánea, y es lo que Paz trató de defender frente a quienes se alinearon con el totalitarismo soviético.

Lejos de ser un celebrador dogmático de la idolatría del mercado, Paz reclama como tarea urgente propiciar un diálogo entre las dos tradiciones de pensamiento político más importantes de Occidente: el liberalismo y el socialismo. Frente a quienes celebran la muerte del socialismo y el fin de la Historia, Paz declara que tanto socialismo como liberalismo "[h]an sido los grandes interlocutores de los siglos XIX y XX y tal vez ha llegado la hora de una síntesis. Ambos son irrenunciables, están presentes en el nacimiento de la Edad Moderna: uno encarna la aspiración hacia la liber- tad y el otro hacia la igualdad. El puente entre ellas es la fraternidad, herencia cristiana, al menos para nosotros, hijos de Occidente. Un tercer elemento: la herencia de nuestros grandes poetas $y$ novelistas".

Para concluir habría que señalar algunos aspectos de la conducta intelectual de Octavio Paz. Con él muere uno de los últimos representantes de una singular generación de intelectuales-literatos poseedora de una amplia cultura universal. Propio de esta generación es también resistir la tentación de la torre de marfil y no temer a ensuciarse las manos con los asuntos mundanos. Paz no sólo produjo una obra literaria considerable por su extensión y calidad. Fue un claro protagonista en la vida de su país. Y lo fue tanto en el ámbito literario como en el político; aunque en este último terreno no eligió la vía de la política partidaria sino la del activismo cultural y la intervención libre en el debate público. $Y$ sus posiciones no tienen por qué gustarnos. En particular, no debemos olvidar que Paz insistentemente tendió a disminuir el peso de justicia de muchos de los reclamos enunciados desde los movimientos de izquierda.

Pero lo último no es suficiente motivo para negar a Octavio $\mathrm{Paz}$ un doble mérito: en primer lugar, emplear un singular talento literario para contribuir a esclarecer los problemas más urgentes de la existencia humana en su compleja diversidad; en segundo lugar, la lucha por asegurar al intelectual una posición independiente y crílica frente a los poderes establecidos. Y en esta última lucha la libró no sólo ante los poderes económicos y políticos, sino ante las sutiles modalidades de cohersión implícitas en los hábitos de pensamiento institucionalizados.

Ricardo Roque Baldovinos 